\title{
Health Service Quality and Its Impact on Strategic Success: A Field Study on the Private Hospitals of Jordan
}

\author{
Abdullah Abbas Al-khrabsheh ${ }^{1}$, Omar Rabeea Mahdi ${ }^{2}$ \& Ahmed Kh. Muttar ${ }^{2}$ \\ ${ }^{1}$ Prince Al-Hussein Bin Abdullah II Academy of Civil Protection, Al-Balqa Applied University, Jordan \\ ${ }^{2}$ Applied Science University, Bahrain \\ Correspondence: Abdullah Abbas Al-khrabsheh, Prince Al-Hussein Bin Abdullah II academy of Civil Protection, \\ Al-Balqa Applied University, Jordan. E-mail: abdbbs@gmail.com
}

Received: July 12, 2017

doi:10.5539/ijbm.v12n10p185

\author{
Accepted: August 20, $2017 \quad$ Online Published: September 17, 2017 \\ URL: https://doi.org/10.5539/ijbm.v12n10p185
}

\begin{abstract}
The study aimed at identifying the dimensions of the quality of health service and its impact on strategic success. In order to achieve the objectives of the study, the analytical descriptive method was used. The population of the study represented all private Jordanian hospitals. Due to the difficulty of reaching the whole study population, the researcher took a random sample. The number of questionnaires distributed was (220) questionnaires, of which (200) were returned. The study also concluded that the importance of quality of service in private hospitals was medium. The study recommended that the importance of quality of service should be enhanced as a part of the strategic vision when constructing the strategy in private hospitals as it received the weakest degree and the same applies to the importance of strategic success and achievement of hospital goals.
\end{abstract}

Keywords: Quality of service, reliability, strategic success

\section{Introduction}

The health sector is one of the most important indicators of the development and progress of the societies of the world. This is an important aspect for the health sectors due to the nature and type of services provided by the hospitals, which relate to the health and lives of individuals as well as the beneficiaries of these services. Most of the developmental plans in poor countries focus on improving and developing the health sector and exert more efforts to support the health sector.

In this regard, the importance of quality of health service, represented by (concrete, guarantee, empathy, reliability and responsiveness) has been explored in order to reach the desired degree of the quality of health services as required by the individuals of the community. This dimension has clarified most of what can be measured in the quality of service. However, the quality of the health service offered to individuals in the community by hospitals is one of the important factors affecting the satisfaction of the beneficiaries. This is what has been proven by the studies. Therefore, most of the studies in this field focused on measuring the quality of the health service.

This strategic success has always been the goal of all organizations in the world, including health organizations (hospitals), which seek to achieve this goal by consolidating and intensifying their efforts. As medical hospitals are administrative systems that use a wide range of physical, human, technological and scientific tools to provide health services and increase the quality of hospital services, then those concerned with the health sector should direct efforts to determine the impact of the service on many factors, including strategic success.

Strategic success, which is the primary requirement of leading hospitals in the field of health services, is a set of sub-goals that are based on several strategic themes (customer focus and satisfaction, growth and learning, internal operations, and financial hub). Accordingly, strategic themes are strongly related to strategic success.

Due to the importance of both quality of service, strategic success, impact on the functioning and functioning of hospitals, this study iintends to shed light on each of them and to show the impact of the dimensions of those services provided by private hospitals in Jordan.

In this context, this study focused on the private hospitals sector in Jordan as representing (57.5\%) of the total number of hospitals in the Kingdom which report to the Ministry of Health, Medical Services, University 
Hospitals and private hospitals comprising 106 hospitals. The number of private hospitals in Jordan amounts to (61), distributed throughout the Kingdom, of which (39) are in Amman, the capital, or (63.9\%) of the total private hospitals in Jordan that are located in Amman the capital (Annual Report, Ministry of Health, 2012).

Based on the above, this study attempts to examine the impact of the dimensions of the quality of health services and to clarify the basics and the importance of the organizations and their impact achieving the strategic success within the specific strategic themes, by using a clear scientific methodology, analysis and conclusion to help strengthen the foundations of health work and help to develop a model proposed by organizations. This intends to achieve and raise the level of strategic success as desired in the private hospitals in Jordan.

\section{Problem of the study}

Organizations face many challenges and constraints that limit their ability to achieve their goals, especially hospitals and health service organizations in Jordan. The study aims at showing the impact of the quality of health services on achieving strategic success in private hospitals. The dimensions of quality of service and strategic success in private hospitals include the following questions:

a. What is the level of quality of health services that is provided in the private sector hospitals?

b. Is there a tangible impact on their strategic success?

c. Is there an impact of reliability on strategic success?

\section{Model of the study:}

Independent variables can be identified as a subsidiary of this study through the following form:

The Independent variable

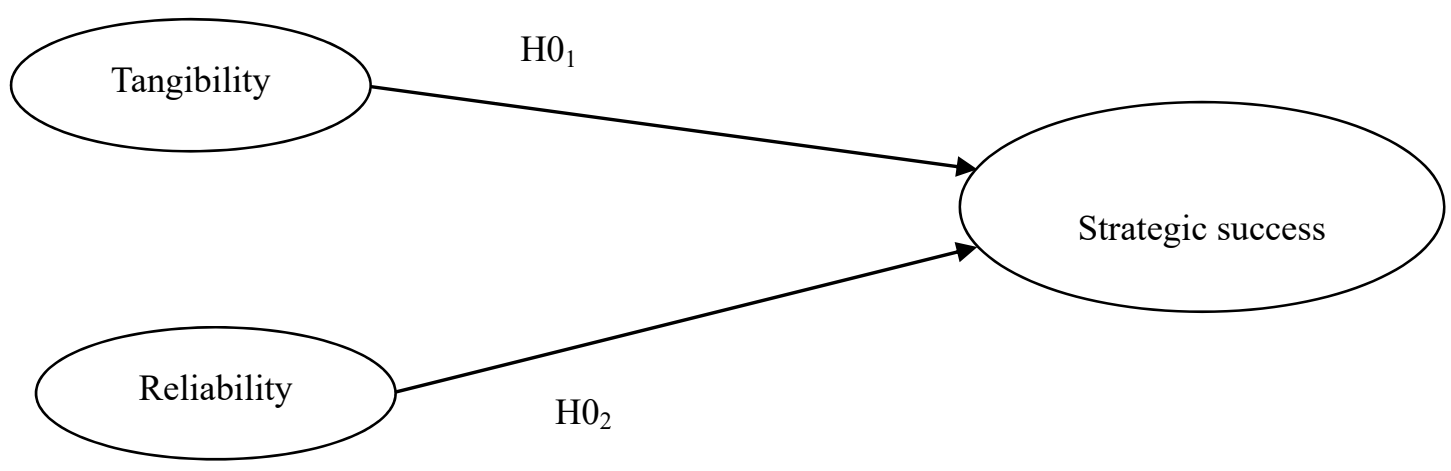

Figure 1. Model of the study

\section{Significance of the Study}

The importance of this study stems from several aspects, including the variables of the study, which link the dimensions of the quality of health service (tangible, reliability) to strategic success.

The study entitled: "Quality of Service, Customer Satisfaction (Behavioral) and Behavioral Intentions in Healthcare Services: Exploring the Indian Perspective," explores the healthcare sector in India as a more competitive sector, where healthcare practitioners and academic researchers are increasingly interested in exploring how patients view quality before building levels of satisfaction and generating behavioral intentions.

Currently, hospitals are increasingly aware of the need to focus on the quality of services as a measurement to improve their competitive position. Therefore, customer-based determinants and customer perceptions about the quality of service play an important role when choosing a hospital.

In this paper, the researcher examines and measures the quality and outcomes of services (patient satisfaction and behavioral intentions) provided by hospitals. The researcher reviewed literature on patient satisfaction and behavioral intentions, with an investigation of the direct impact of QoS on behavioral intentions and the role of mediation in customer satisfaction that influence behavioral intentions.

In addition, the study focuses only on health care services provided by hospitals. To date, few studies have been conducted in developing countries to understand the types of relationship between three basic types of quality of 
service, patient satisfaction and behavioral intentions. Most studies have been conducted in the developed countries, which cannot be generalized for the Indian context. Building quality of service that is developed in one culture may not be applicable in another one. This study analyzes the appropriateness of service quality to improve customer satisfaction, and in a process that positively influences behavioral intentions in the health care setting.

\section{Previous Studies}

The study of Rezarta et al. (2016), "Service Quality Assessment in Health Care Sector: The Case of Durres Public Hospital", aims to assess the quality of services in the general regional hospital of Durres, as one of the most important in Albania, given that quality is a key parameter in performance assessment. Patients are key actors in quality assessment and evaluation. This study is based on a completed questionnaire of 200 patients in hospital between July and September 2015. The survey is based on the Service model using five dimensions of service quality such as empathy, responsiveness, responsiveness, assurance and reliability. They measure the perceptions and expectations of patients in each of them. Data identification and treatment Identification of key factors affecting patient preferences in general where results in particular show positive results towards quality services without significant differences between expectations and actual patient perceptions. In this context, the conclusions and conclusions reached should be taken into account as very important aspects for hospital managers as well as policymakers when dealing with decisions.

In another study by Boboce et al (2016), titled "The management of health care service quality. A physician perspective", the application of marketing in health care services is presented as an essential element for every manager or policy maker. The aim was for the health care organization to succeed in establishing a precise measurement measure to determine the quality of service due to competitive pressures and cost values. The most commonly used domain in the service sector is the Service scale. Although successfully adopted in areas such as mediation and banking, the experts concluded that the SERVQUAL scale should be adjusted according to the specific context. Furthermore, the SERVQUAL standard has focused on the consumer's view of service quality. While quality of service was measured with the help of the SERVQUAL Scale, other experts identified the design of the process and outcome structure, which they believed would be more appropriate for health care services. This approach highlights a different perspective on the quality of service investigation, which is the view of the doctor. Furthermore, we believe that the seven-pronged model for improving quality of service has been adopted for effective measurement of health-care services in a Roman context from the doctor's point of view.

The study of Minesh et al. (2014), titled "Health services quality improvement in Guaymate, Dominican Republic, as the framework for US global health education: a case study", explored the feasibility of a partnership approach between the community, the US Peace Corps and the University of Illinois to improve the quality of local primary health care services in Guimat, Dominican Republic. The goal was to conduct community participatory research (CAPPER) as a framework for global health education for US trainees. We used mixed methods to describe partnership, assess the impact of health services on quality improvement, and consider qualitatively the value of the global health education experience. The outcome variables include partners' contributions and benefits to partnership assessment; client perceptions of access, perceptions of the US trainee on the personal and societal impact of the assessment of global health education. We used a survey to identify local priorities to improve the quality of health services. As part of the partnership, the leadership of the local health institution guides the project in the light of local priorities; the Peace Corps provides support in coordination, community experience and local confidence; the academic institution provides technical support, public health and research support. The community benefits by improving access to quality primary health care services. US trainees learn the principles of primary health care, community participation, social determinants of health, and the promotion of health services. Local priorities were identified to improve the quality of health services in the local municipal hospital and community health education

- Bonakitikim (2012) conducted a study titled: "Quality Health Care Service: Case Example of a Hospital with Lean Implementation". The purpose of the study was to measure the quality of service in the hospital's implementation of lean management. The paper evaluates patients' expectations and satisfaction about the quality of hospital services. Data were collected from (450) patients, and then was analyzed using the (Servcual Model). This model compares patients' perceptions and expectations of service received across five dimensions of (QoS), including reliability, responsiveness, affirmation, empathy and tolerance.

- The results of the study showed that overall quality of service is positive, but there are no significant statistical differences between the patients' general perception and their expectations. The quality of 
service in the (Lean Model) implementation was moderate. The hospital is able to provide services as expected. In addition, the largest positive gap between patient perception and expectations were related. The largest negative gap was related to collateral. The results help the management team understand the areas of improvement. Senior management can apply research results to design and prioritize hospital strategies to improve quality of service.

- Rachid (2009), implemented a study titled "Quality of Service in Health Care Mode". This study achieves a definition of quality of service from functional and functional aspects to better understand how consumers evaluate the quality of health care. It adopts the conceptual model of quality of service used by most researchers in the health care sector. The paper also discusses several aspects of quality of service and quality of service problems in order to provide a more comprehensive concept of hospital quality of service.

The purpose of the study was to determine the different dimensions of the quality of service in private hospitals in Iran and to evaluate the quality of service from the patients' point of view. The results showed that "Servcwal" is a tool that is valid, reliable and flexible to monitor and measure the quality of services in private hospitals in Iran. The findings show a strong relationship between patients and practitioners / hospital staff, and the need for hospital staff to be responsive, reliable and patient when dealing with patients.

\section{Summary of the Previous Studies Compared with the Current Study}

Most of the studies focused on assessing the quality of service provided to customers and their impact on customer satisfaction; (Kalisir et al., 2012) and the study of (Amjeriya \& Malviya (2012).

The current study is different from the previous studies in terms of the community in question; depending on the private hospitals sector in particular, the nature of the variables of the study where most of the previous studies focused on the satisfaction and customer loyalty. However, this study will explore the impact of quality of service in private hospitals from the perspective of managers and employees in strategic success.

\section{Methodology of the Study}

The study adopted the descriptive analytical method using a questionnaire to examine and uncover the impact of the quality of health service dimensions according to the opinion of the study sample members of the Jordanian private hospital staff in the strategic success. In addition, the researcher reviewed the theoretical literature that shed light on the dimensions of the quality of health service and strategic success, and related studies, as well as the application of the study tool for data collection and analysis, to reach results that contribute to the set of recommendations.

\section{Population of the Study}

The study population consists of all employees in private hospitals in the Jordanian capital of Amman, according to the report of the Jordanian Ministry of Health. The annual number of private hospitals in the capital is (39) hospitals (The Jordanian Ministry of Health, The Annual Report, 2012 Jordan, Amman).

\section{The study Sample}

A percentage of $(10 \%)$ of employees were selected from 10 private hospitals. The sample of the study represented (25\%) of the number of private hospitals in Amman (39 hospitals).

These hospitals are: Ibn al-Haytham Hospital, Istiklal Hospital, Consultant Hospital, Red Crescent Hospital, Hanan Hospital, Aqla Hospital, Al-Quds Hospital, Mowasat Hospital, Philadelphia Hospital and Heba Hospital. Reference to what was determined by Sekaran (2003), the sample size (30-500) is suitable for most studies, and after the field inspection of the number of workers in the hospitals under study, $(10 \%)$ of the employees were selected from each hospital.

The sample of the study at all levels of management was selected by selecting staff from all departments in the hospital. The number of questionnaires distributed was (220) questionnaires, of which (207) were returned and (7) were rejected, which makes the number of valid questionnaires for analysis (200) problem questionnaire $(90 \%)$ of the study sample, and are described as in the following table: 
Table 1. Number of study sample members

\begin{tabular}{llll}
\hline Number & Hostipal & Employee & Questionnaire / \\
\hline 1 & Ibn al-Haytham & 620 & 62 \\
2 & AL-Istqlal & 500 & 50 \\
3 & AL-Astsary & 460 & 46 \\
4 & Helal & 95 & 10 \\
5 & Hanan & 145 & 15 \\
6 & AQELA & 70 & 7 \\
7 & Qudas & 65 & 7 \\
8 & AL-Moasa & 90 & 9 \\
9 & Philadelphia & 65 & 7 \\
10 & Hiba & 70 & 7 \\
Total & & 2180 & 220 \\
\hline
\end{tabular}

\section{Instrument of the Study}

A study tool was designed to achieve the goals of the study and to know the dimensions of the health service quality and its impact on strategic success. A number of studies were used such as the study that was conducted by Diab (2012), Taweel and his colleagues (2010), Hunger \& Wheelen, 2008) and Strickland et al. (2008). The five-dimensional Likert scale was used to identify the perspectives of the participants of the sample.

\section{Validity}

This was done in order to verify the veracity of the questionnaire. It was presented in its preliminary form to a number of referees who are competent in the field of administration, marketing, and finance, in order to verify the validity of the content of the questionnaire, the extent of affiliation of each paragraph of the questionnaire, as well as language formulation.

The questionnaire was written in its final form based on the observations and suggestions of the referees, where the researcher made the necessary amendments. Each paragraph was obtained with the approval of $(80 \%)$ of the members of the jury.

\section{Stability of the Study Instrument}

The stability of the study instrument was confirmed using the (Cronbach Alpha) equation and it was found that the stability coefficients were as shown in the following table:

Table 2. Stability coefficients of the study instrument using the Alpha Kronbach equation

\begin{tabular}{ll}
\hline SECTION & Cronbach's coefficient \\
\hline Tangibility & 0.83 \\
Reliability & 0.85 \\
Total & 0.84 \\
\hline
\end{tabular}

From the above table, the stability coefficients of the resolution dimensions ranged from (0.83 to 0.85$)$. This means that the questionnaire has a stable coefficient for the purposes of the current study.

\section{Statistical Processing}

Statistical analysis of the data was done using a set of statistical methods through the Statistical Package for Social Science (SPSS).

1- The Multiple and Simple Regression Factor: To test the first main hypothesis and the associated sub-assumptions.

2- Cronbach Alpha equation: To verify the stability of the study instrument.

3- Frequency, percentages, arithmetic averages and standard deviation: To describe the sample members of the study.

\section{Discussion of the Study Results}

The results of the study will be discussed by answering the following questions: 
First: What is the level of quality of health service in the private sector hospitals?

To identify the reality of the quality of health service in the private sector hospitals, the study used the arithmetical averages, the standard deviations, the degree of importance of the paragraph and the level of approval.

Table 3. The mean and standard deviations and the order of importance of the responses of the sample members of the study on the reality of quality of health service in private hospitals

\begin{tabular}{lcc}
\hline Questions & Mean & Std. Deviation \\
\hline Tangibility & 3.73 & 0.67 \\
1-The hospital building has a distinctive and attractive architectural design & 3.73 & 0.68 \\
2-The hospital has the latest medical equipment and equipment & 3.83 & 0.80 \\
3-The hospital furniture features a distinctive and comfortable design & 3.66 & 0.68 \\
4-The hospital offers convenient facilities and lounges to wait for patients & 3.83 & 0.60 \\
5-The hospital is characterized by a high degree of cleanliness and order & 3.83 & 0.62 \\
6-The medical and administrative staff is characterized by a high degree of cleanliness and distinctive appearance & 3.87 & 0.60 \\
7-The interior design of the hospital has corridors for people with special needs & \\
Reliability & 3.86 & 0.59 \\
8-The hospital provides services expected by patients & 3.87 & 0.60 \\
9-The hospital staff has sufficient knowledge to provide services in all specialties & 3.77 & 0.64 \\
10-Patients receive timely service from the first time & 3.79 \\
11-The hospital maintains high-accuracy databases for patients and reviewers & 0.62 \\
Total & 3.80 & 0.585 \\
\hline
\end{tabular}

Table (3) shows that the average quality of health services in the private sector hospitals was (3.80) with a standard deviation of (0.585). From Table (3) there was an average of (3.78) and (0.59) of standard deviation (0.59). At the level of the paragraphs, the first rank was presented in paragraph (7). The internal design of the hospital contains special needs corridors, with an arithmetic average of (3.87) and a standard deviation of $(0.60)$.

The last rank in paragraph (4) states: "The hospital has convenient facilities and facilities to wait for patients' escorts" with an average of (3.66) and a standard deviation of (0.68).

The area of reliability achieved a general accounting average of (3.82) and a general standard deviation (0.58). At the level of the paragraphs, the first rank was given to paragraph (9), "The medical staff at the hospital has sufficient knowledge to provide services in all disciplines." The mean was (3.87) whereas the standard deviation was $(0.60)$. The paragraph "Patients receive the required service on time from the first time" had an arithmetic average of (3.77), with a standard deviation (0.64).

The second question: Is there a statistically significant effect between a tangible dimension and the strategic success at significance $(\alpha=0.05)$

To verify this question, a simple regression analysis technique was used to verify the impact of the significant dimension of strategic success as a dependent variable, as shown in Tables $(4-7)$.

Table 4. Variables entered/removedb

\begin{tabular}{llll}
\hline Model & Variables entered & Variables removed & Methods \\
\hline 1 & Total2 $^{\mathrm{a}}$ & & enter \\
\hline a. all requested variables entered & & \\
b. dependent variable: total & &
\end{tabular}

Table 5: Model summary

\begin{tabular}{lllll}
\hline Model & $\mathrm{R}$ & R Square & Adjusted R Square & Std.error of the estimate \\
\hline 1 & $0.440^{\mathrm{a}}$ & 0.193 & 0.184 & 0.4144 \\
\hline
\end{tabular}

a. predictors:(constant), total2. 
Table 6. ANOVA ${ }^{\mathrm{b}}$

\begin{tabular}{lllllll}
\hline Model & & Sum of squares & Df & Mean square & F & Sig. \\
\hline 1 & Regression & 3.417 & 1 & 3417 & $.000^{\mathrm{a}}$ \\
& Residual & 14.253 & 83 & 0.172 & \\
& Total & 17.670 & 84 & & \\
\hline
\end{tabular}

a. Predictors: (constant), Total2.

b. Dependent variable: Total.

Table 7. Coefficients ${ }^{\mathrm{a}}$

\begin{tabular}{|c|c|c|c|c|c|c|}
\hline \multirow[t]{2}{*}{ Model } & & \multicolumn{2}{|c|}{ Unstandardized coefficients } & \multirow{2}{*}{$\begin{array}{l}\text { Standardized } \\
\text { coefficients } \\
\text { Beta }\end{array}$} & \multirow[t]{2}{*}{$\mathrm{t}$} & \multirow[t]{2}{*}{ Sig. } \\
\hline & & $\mathrm{B}$ & Std.error & & & \\
\hline \multirow[t]{2}{*}{1} & (constant) & 2.260 & 0.389 & & 5.811 & 0.00 \\
\hline & Total2 & 0.446 & 0.100 & 0.440 & 4.461 & 0.00 \\
\hline
\end{tabular}

a. Dependent variable: Total.

Tables (4-7): Results of the simple regression analysis test to measure the after-effects impact of strategic success * The effect is statistically significant at $(\alpha=0.05)$

Tables (4-7) shows the tangible effect of strategic success. The results showed that there is a statistically significant effect between the significant dimension of strategic success. The coefficient of correlation is at $(0.05$ $=\alpha$ ), that is, the value of (0.674) of the changes in strategic success are attributed to the change in the standard level and the value of the degree as well. This means that the increase in the level of increases the strategic success with a value. The significance of this effect confirms the calculated $F$ value of (19.898), which is statistically significaant at $\alpha(0.05)$. This means rejecting the first zero-negative hypothesis and accepting the alternative hypothesis which states: There is a statistically significant effect between the concrete dimension of the strategic success at the level of significance $(\alpha=0.05)$

The third question: Is there a statistically significant effect between the reliability of the strategic success at the level of significance $(\alpha 0.050 .05)$

To determine the existence of such effect, a simple regression analysis technique was used to verify the effect of reliability on strategic success as a dependent variable, as shown in Tables $(8-11)$

Table 8. Variables entered / removed $^{\mathrm{b}}$

\begin{tabular}{llll}
\hline Model & Variables entered & Variables removed & Methods \\
\hline 1 & FIVE $^{\mathrm{a}}$ & & Enter \\
\hline a. all requested variables entered. & & & \\
b. dependent variable: Total. & & &
\end{tabular}

Table 9: Model summary

\begin{tabular}{lllll}
\hline Model & $\mathrm{R}$ & R Square & Adjusted R Square & Std.error of the estimate \\
\hline 1 & $0.333^{\mathrm{a}}$ & 0.111 & 0.100 & 0.4351 \\
\hline
\end{tabular}

a. predictors:(constant), FIVE.

Table 10. ANOVA b

\begin{tabular}{lllllll}
\hline Model & & Sum of squares & df & Mean square & F & Sig. \\
\hline 1 & Regression & 1.956 & 1 & 1.956 & 10.330 & $.000^{\mathrm{a}}$ \\
& Residual & 15.714 & 83 & 0.189 & & \\
& Total & 17.670 & 84 & & & \\
\hline
\end{tabular}

a. Predictors: (constant), FIVE.

b. Dependent variable: Total. 
Table 11. Coefficients ${ }^{\mathrm{a}}$

\begin{tabular}{|c|c|c|c|c|c|c|}
\hline \multirow[t]{2}{*}{ Model } & & \multicolumn{2}{|c|}{ Unstandardized coefficients } & \multirow{2}{*}{$\begin{array}{l}\text { Standardized } \\
\text { coefficients } \\
\text { Beta }\end{array}$} & \multirow[t]{2}{*}{$\mathrm{T}$} & \multirow[t]{2}{*}{ Sig. } \\
\hline & & B & Std.error & & & \\
\hline \multirow[t]{2}{*}{1} & (constant) & 2.993 & 0.312 & & 9.602 & 0.00 \\
\hline & FIVE & 0.252 & 0.078 & 0.333 & 3.214 & 0.002 \\
\hline
\end{tabular}

a. Dependent variable: Total.

Tables (8-11): Results of the simple regression analysis test for measuring the impact after dependence on strategic success * The effect is statistically significant at $\alpha(0.05)$

Tables (8-11) show an effect which is attributed to the strategic success, where the results showed statistical significant effects due to strategic success. The coefficient of correlation $(0.333)$ was at $(\alpha=0.05)$, the value of changes in the strategic success due to the change in the level of dependence and the value of the degree of influence.

This means that the increase in the level of dependence leads to an increase in success of strategic value. The significance of this effect confirms the calculated value of $\mathrm{F}$ (10.330), which is a function at $\alpha(0.05)$.

This means rejecting the second zero hypothesis and accepting the alternative hypothesis which states: There is a statistically significant effect between the reliability of the strategic success at the level of significance $(\alpha=0.05)$.

\section{Findings and Conclusions}

The study raised many questions and presented hypotheses related to the nature of the relationship and impact of the quality of health services by the dimensions on the strategic success. It was concluded that such dimensions contribute to solving the problem of the study, answer the questions and test the hypotheses.

1- The quality of health service in private hospitals was average (3.80), with a standard deviation of (0.585).

2- The results indicated that the level of palpation in the service provided by private hospitals is high, with a general average of (3.78) and a general deviation of (0.59).

3- The results indicated that the level of reliability in the service provided by private hospitals is high, with a general average of (3.82) and a general deviation of (0.58).

The results indicated that there is a statistically significant effect between the two dimensions of reliability and the materiality in the strategic success at a level of significance $(\alpha \leq 0.05)$

\section{Recommendations}

In light of the findings and conclusions of the study, the researcher would recommend the following:

1- Private sector hospitals can improve the quality of their services as a part of the strategic vision when building the strategy in private hospitals by emphasizing sympathy, since this dimension obtained the weakest degree of quality of health service and its importance in strategic success to achieve hospital goals.

2- Private sector hospitals shall comply and put emphasis on establishing high standards for the quality of services provided to cover all dimensions and should be tested and modified periodically, which will in turn increase the degree of sympathy and avoid obtaining the lowest degrees. This can be acheived through the establishment of specialized departments in quality control.

3- Staff's punctual committment to provide services to patients and take into account satisfying their urgent needs and desires.

\section{Referencies}

Bobocea, L., Gheorghe, I. R., Spiridon, S. T., Gheorghe, C. M., \& Purcarea, V. L. (2016). The management of health care service quality. A physician perspective. Journal of Medicine and Life, 9(2), 149-152.

Calisir, F., Gumussoy, C. A., Bayraktaroglu, A. E., \& Kaya, B. (2012). Effects of Service Quality Dimensions on Customer Satisfaction and Return Intention in Different Hospital Types, International Conference on Industrial Engineering and Operations Management Journal , 3(6), 518-521.

Horng, C., \& huarng, F. (2002). TQM adoption by hospitals in Taiwan. Francis Group, 13(4), 441-463. https://doi.org/10.1080/09544120220149269

Iranzadeh, S., \& Chakherlouy, F. (2012). Service Quality Dimensions in the Banking Industry and It's Effect on 
Customer Satisfaction (Case Study). Scientific Journal, 5(40), 87-100. https://doi.org/10.5772/38641

Malviya, R. K., \& Amjeriya, D. (2012). Measurement of Service Quality in Healthcare Organization. International Journal of Engineering Research \& Technology, 1(8), 1-16.

Miller, P., \& Yasin, M. M. (2005). An empirical investigation of quality improvement initiatives in for-profit and not-for-profit hospitals in Tennessee, USA. Retrieved from http://www.emeraldinsight.com

Minesh, S., Andrew, D., Amy, H., Shannon, G., \& Juliet, S. (2014). Health services quality improvement in Guaymate, Dominican Republic, as the framework for US global health education: A case study. The LANCET Global Health Journal, 2(41), 70-98.

Ping, C. T., Suki, N. M., \& Suki, N. M. (2012). Service Quality Dimension Effect on Customer Satisfaction towards E- Banking. Interdisciplinary Journal of Contemporary Research in Business, 4(4), 741-751.

Rezarta, K., Red, M., \& Francesco, S. (2016). Service Quality Assessment in Health Care Sector: The Case of Durres Public Hospital. Procedia - Social and Behavioral Sciences Journal, 235(14), 557-565.

Sekaran, U. (2003). Research Methods for Business: A Skill Building Approach (4th ed.). New Jersey: John Willey \& Sons Inc.

Shanka, M. S. (2012). Bank Service Quality Customer Satisfaction and Loyalty in Ethiopian Banking Sector, Journal of Business Administration and Management Sciences Research, 1(1), 1-9.

Strickland, A. J., Jr Thopmson, A. A., \& Gamble, J. E. (2008). Crafting and executing strategy-the quest for competition advantage concepts and cases (16th ed.). MC Graw Hill Icn.

Wheelen, T. L., \& Hunger, J. D. (2008). Strategic Management and business policy (11th ed.). Pearson prentice hall, USA.

\section{Copyrights}

Copyright for this article is retained by the author(s), with first publication rights granted to the journal.

This is an open-access article distributed under the terms and conditions of the Creative Commons Attribution license (http://creativecommons.org/licenses/by/4.0/). 